\title{
The Relationship Between the Change of Original Motivation and Social Adaptation of Exchange Students in China
}

\author{
Keyi Zhang ${ }^{1 *}$ \\ ${ }^{1}$ Fujian Normal University, Fuzhou 350117, Fujian, China \\ *Corresponding author. E-mail: 1149789035@qq.com
}

\begin{abstract}
With the further development of international academic exchanges, multinational study has become increasingly popular. Driven by different motivations, the number of foreign students come to China is also on the rise. This paper address that the original motivation of exchange students exert an influence on the continuous improvement of their social adaptability in China, which will affect their future planning after graduation.

Method is employed to macroscopically analyze the original motivation of foreign students, compare the differences in the development plans of foreign students after completing the established studies, and finally explore the influence of social adaptability on original motivation.

Based on the obtained research, the following conclusion can be drawn that most exchange students in China are more likely to stay in China for further study or start their career than to return to their hometown after finishing their established study career.

This study provides some ideas for improving the exchange student policy. In order to better promote the cultivation of international talents, the exchange student policy should make up for the shortage of preparatory work before they begin multinational study. Moreover, improve the guidance of career development in China after graduation. It is aimed to establish more well-developed service system including the study and employment for exchange students in China.
\end{abstract}

Keywords: Exchange students, social adaptation, exchange student policy, international talents

\section{INTRODUCTION}

With the deepening of internationalization of Higher Education and the spreading of Chinese culture, plenty of foreign students come to China for the short-term education. Generally speaking, the duration of exchange program is divided according to the Chinese education system. There are two or three months of special program training in summer and winter vacation, three years of middle or high school, and two years of undergraduate or master's degree courses. Statistics from the Ministry of Education showed that 86.1 percent of overseas students planned to have short-term internships in China, and 95 percent wanted to stay and work in China. Among them, 64.7 percent expressed a desire to stay in China and work in an overseas organization, and 70.1 percent said they wanted to work in a multinational company in China.[10] It is shown that most exchange students in China are more likely to stay in China for further study or start their career than to return to their original place after finishing their established study career. Due to the difference advancement of social adaptability and living experience, different results of career planning come out.

Most of the related studies focus on the isolated study of cross-cultural adaptation, and do not link adaptation with the change of original motivation. We consider that the change in the original motivation as a possible consequence of adaptation. This paper plans to analyzes the changes of adaptability of foreign students on the basis of the original motivation, so as to make up for the lack of relevant research. Meanwhile, what can be done is that tracing back to the source of advantages and disadvantages of the contemporary exchange student policy for the dissemination of culture and 
guidance for adaptation. It aims to put forward some suggestions to solve the problems in practice.

\section{ORIGINAL MOTIVATION}

The original motives of exchange students to come to China include advantaged policy attraction, overseas Chinese returning home and personal interest.

\section{1. "The Belt and Road"}

As of April 25, 2019, China's policy named The Belt and Road has been introduced and the proposal of educational initiatives aimed at cultural exchange has been widely recognized and appreciated by the countries along the way and the international community.

The Belt and Road has been signed by the China Ministry of education, and the 24 countries along The Belt and Road have signed mutual recognition agreements. A total of 60 colleges and universities have been running overseas in 23 countries along the line. 16 colleges and universities have established 17 international cooperation laboratories with the Ministry of Education along with the universities [10]. According to the statistics of the Ministry of Education, in 2018, a total of 492,185 foreign students from 196 countries and regions studied in 1,004 institutions of higher learning in 31 provinces, autonomous regions and municipalities, an increase of 3,013 over 2017, with an increase of $0.62 \%$ (the above data do not include Hong Kong, Macao and Taiwan) [11]. Until December 22, 2020, the Ministry of Education held a press conference to introduce the opening up of education during the 13th Five-Year Plan period. Liu Jin, director of the Department of international cooperation and exchange of the Ministry of education, said that in 2019, the proportion of international students with academic degrees in China will reach $54.6 \%, 7$ percentage points higher than that in 2016. [12] By the end of 2020, there are 2332 Chinese joint education and projects, including 1230 with bachelor degree or above. During the period of 13th Five-Year Plan, in accordance with the overall plan of comprehensively deepening education reform, efforts have been made to strengthen system construction and institutional innovation in education opening to the outside world. The measures for the administration of recruiting and training international students, the quality standard of higher education for international students in China (for Trial Implementation) and the measures for the administration of scholarship work of the Chinese government have been issued to standardize the qualification conditions for universities to accept international students, continuously improve the quality standard and supervision system for international students in China, and continuously optimize the structure of international students in China. During the 13th Five Year Plan period, the Ministry of Education approved and recorded 580 Chinese foreign cooperatively run schools and projects ( 7 independent legal entities, 84 non independent legal entities and 489 projects), including 356 with bachelor degree or above. Foreign affairs management focuses on streamlining administration and delegating powers, granting "double first-class" construction universities certain foreign affairs approval power and providing greater autonomy and convenience for universities to carry out foreign cooperation and exchange. In order to standardize the quality of studying abroad and improve the supervision system and optimize the structure, china published Administrative Measures for Recruiting and Training International Students and Measures for the Administration of Scholarship Work of the Chinese Government [13].

Under the "One Belt And One Road" initiative, Chinese government focuses on providing financial and spiritual support for exchange students. So as to give full play to the role of cultural exchange, culture and communication, and make use of teaching resources and advantages to attract foreign students come to China for education. By this way, the cultural cooperation and exchanges between China and countries along the Belt and Road are becoming more extensive and in-depth.

\subsection{Special for Overseas Chinese}

The growing number of overseas Chinese return home with their offspring. On the one hand, with the rapid development and progress of China, the sense of national pride and cultural identity of overseas Chinese has been gradually enhanced. For overseas Chinese, it attaches great importance to the return of their offspring to learn Chinese and receive Chinese education. On the other hand, China has introduced considerable favorable policies to attract overseas Chinese to return to China for development. What is more, special preferential policies are provided for Chinese businessmen to improved their political status. For example, based on China's education system, the Ministry of Education issued relevant preferential policies, for example, 10 points increased in Gaokao for returned overseas Chinese, children of overseas Chinese, returned overseas Chinese and Taiwan provincial (including registered residence) candidates.

While introducing high-level talents, China also resettled the descendants of overseas Chinese to solve the problem of education for their offspring.

China adheres to the principle of cultural inclusion, fully respects the cultural tradition of the country where overseas Chinese have lived, and gradually infiltrates Chinese traditional culture. By this way, it explores the intersection and common place of different cultural systems. For example, there are obvious similarities between Christmas in Europe and Spring Festival in China, and both of which are the hope and desire for a better and happy life. 


\subsection{Personal Motivation}

What cannot be ignored is that China is committed to promoting Chinese traditional culture in the world. In this way, diverse culture attract tons of oversea students come to china for education. in conclusion, the main personal motivation is career planning and culture attraction.

Individual motivation that influence educational planning are mostly oriented by the demand of the job market. In the current highly globalized social and economic environment, employees are required to be able to put forward a response rapidly to the change of internationalization. In this international social background, the job market is in urgent need of international talents. Therefore, Studying abroad is to acquire international knowledge and skills, and to have an international vision and strategy becomes a kind of essential ability and quality. Exchanges and cooperation between countries require communication workers who are familiar with the cultures and languages of the two countries. A large number of staff who are familiar with the cultures of both are needed, which provides a big motivation for exchange students studying in China.

Some scholars used Cobb-Douglas production function to study the panel data of 29 provinces in China from 1999 to 2015, and found that overseas students, especially along the "One Belt And One Road"The number of foreign students studying in China has a significant effect on economic growth [1]. Personal motivations that influence educational plans vary with the demands of the job market, the bilateral trade advancement is also facilitated by the influx of talent that meets the needs of current markets. A typical case is that with the rapid development of trade between Thailand and China, there will be growing number of companies conduct bilateral trade, and abundant staff familiar with bilateral trade between Thailand and China will be requested. These Thai international students who are proficient in Chinese and understand Chinese culture will be the best candidates. As an important constituent country along the "The Belt and Road" route, Thailand has a large number of Chinese products exported to Thailand. Along with the strengthening of strategic cooperation, Chinese enterprises will make a large amount of investment in Thailand. The investment cooperation between Thailand and China is getting deeper and deeper. The enterprises of both sides, especially Chinese enterprises, need more talents who understand the Thai and Chinese cultures, which is a great benefit for Thai students studying in China.

After more than 30 years of economic reform and opening up, China has made world-famous achievements that are admired by people all over the world, which also sets off a boom in foreign countries to learn Chinese society, economy and culture, and has aroused great interest in China's mysterious traditional culture and modern contemporary knowledge. Furthermore, The Chinese government has given full support to the education of the Chinese language. The colorful Chinese activities and other forms of promotion not only touched the Chinese and overseas Chinese, but also made the exchange students more active in learning Chinese and helped them better understand Chinese culture. With the support of the Overseas Chinese Affairs Office of the People's Republic of China, various summer camp activities were organized by various overseas Chinese federations. The Chinese language and various kinds of Chinese culture has been widely promoted. At the same time, due to the active spread and absorption of Chinese culture by the overseas Chinese, their descendants are ecouraged to come to China to feel the Chinese cultural atmosphere.

\section{ANALYSIS OF ADAPTABILITY}

Their exchange life in china includes two main aspects: study daily and social life, which point to two adaption topic:academic adaption and social adaption. From the perspective of individual students, it is the physiological and psychological adaptation of students that plays an important role in academic adaptation and social adaptation.

\subsection{Psychological Adaptation}

Psychological adaptation will directly affect the academic adaptation and social adaptation of international students [3][4]. Academic adaptation refers to students' success in coping with various educational needs, such as motivation, performance and satisfaction with the academic environment. Even if exchange students need to pass a certain level in language examination before they come to China, exchange students still need to immerse themselves in a new cultural background and language environment. A sense of unfamiliar will aggravate psychological pressure, which may be reflected in the difficulty of understanding academic problems [7].

Lysgaard's U-shaped curve hypothesis, Oberg's four stage theory and gullahorn's W-shaped curve hypothesis are the representative research results on the psychological changes of international students from the perspective of cross-cultural time [5][6]. Lysgaard, after investigating the Norwegian students who went to the United States to study, put forward that the travelers will go through three stages when they come to a new culture: the initial adjustment stage, the crisis stage and the recovery and adaptation stage, showing a U-shaped fluctuation trajectory. This model has become a classic theory of cross-cultural adaptation research, and many scholars continue and improve this theory. Oberg put forward four stages of cultural adaptation, namely 
honeymoon stage, depression or hostility stage, adjustment stage and adaptation stage. After the initial honeymoon period of alien culture, the travelers will face the crisis of cultural shock at the bottom of the $\mathrm{U}$-shape, and then reach the top of the U-shape through adaptation and adjustment. In addition, gullahorn added the adaptation stage of "returning to cultural shock" to return to the original cultural environment, further expanded the cross-cultural adaptation curve into a W-shaped curve, and described the process of cultural adaptation and re adaptation of foreign students and visiting scholars.

\subsection{Physiological adaptation}

Physiological adaptation is the basic need to cross the region, and the two aspects that the change of living region has a significant impact on people's life are the change of eating habits and the change of climate.

Diet adaptation has a strong link with interpersonal communication and other basic and inevitable aspects of daily life. Therefore, in the process of adapting to Chinese diet, foreign students should not only accept the differences in taste, food materials and diet style at the individual level, but also to get used to the establishment of interpersonal relationships through diet, as well as adapt to eating habits and etiquette.[8] In the beginning, international students may have difficulty adapting to sudden changes in the dishes, ingredients and cooking methods. Fortunately, Chinese food is characterized by its broadness and profundity, with rich dishes and diverse practices, which makes exchange students with different preferences have more opportunities to find acceptable food, objectively provides more solutions for foreign students with different dietary preferences, and alleviates the impact of cultural differences to a certain extent. At present, all kinds of universities provide a variety of dishes, and they also provide special food according to religious beliefs, so as to alleviate the conflict about dietary taboos.

Climate change is also a crucial factor affecting the cross regional living. The living environment affects the health of exchange students. Too hot and humid area may cause heatstroke and other diseases, too cold and dry environment is more difficult to adapt. With the support of the government, the school is also committed to providing a good living environment for international students. Dormitories are equipped with air conditioning and heating facilities to adjust the room temperature in the purpose of helping international students adapt to the climate as soon as possible.

\section{DISCUSSION}

Relevant measures should run through the whole process of exchange students coming to China.
On the basis of cultural exchange and internationalization of education, the government should not only spread Chinese culture and showcase our excellent educational environment to encourage overseas students to come to China. At the same time, the relevant government departments of our country should guide the countries along the $B \& R$ to strengthen the propaganda of our traditional culture based on the international environment and cultural background. In addition, for study-abroad institutions or foreign institutions, higher education institutions in $B \& R$ countries should do a good job in relevant cultural and educational work before the students start their study abroad career. The goal is to provide international students with an in-depth understanding of China's cultural system before they come to China.

The career planning of international students after the completion of the established study reflects that the environment can have a fundamental impact on people's concept.The learning environment at school is particularly essential. Cultural courses are the direct means and main channels to enhance Chinese cultural identity of exchange students, and the important media for colleges and universities to help them integrate into the traditional cultural environment of China. However, in order to construct effective cultural courses, it is necessary to combine the Cognitive Law of exchange students with curriculum objectives. Then help them to improve their cultural literacy, and form the consciousness and ability to explore Chinese traditional culture independently. It is needed to carry out corresponding subject to improve the understanding of Chinese traditional culture for international students. The main content includes: cultural origin, development course and so on. Moreover, through organizing experiential activities such as calligraphy competition, tea production activities, and Chinese painting exhibition activities, international students can truly understand Chinese traditional culture as well as feel the charm of traditional culture.

This enlightens us: to deal with the education of international students, we should not only focus on providing them with high-quality education during their study, but also focus on building a service system of entrepreneurship and employment in China. It is of benefit for Offering career planning courses for exchange students those stay in China for further study or work. Therefore, the employment and entrepreneurship service system for international students should meet the following requirements: information release, consultation and social practice. The effective integration of career services and academic education can enhance the integrity of education and cultivate international talents.It should also provide rich entrepreneurship platforms to meet the entrepreneurial needs of international students in China and promote their innovation ability.It is advised that 
strengthen connection and cooperation between enterprises and public institutions ought to be placed. It is better to help exchange students understand the employment situation in China through relevant lectures and other forms, so as to make a suitable career plan in the future.

\section{CONCLUSION}

Based on the purpose, this paper presents that the adaptability of international students has an impact on their original motivation. Therefore, result in the change of the extension of their staying in China.

As shown in this study, the primary motivation of overseas students to come to China can be divided into the following three aspects: the attraction of China's favorable policies, the special preferential treatment of overseas Chinese returning to China, and personal academic pursuit and career planning. Attracted by the original motivation, considerable overseas students come to China to seek education. On the basis of the corresponding help provided by the Chinese government and universities and the continuous improvement of their self-adaptation ability, exchange students will gradually adapt to the Chinese society.Then actively expand their social circle in China and get positive feedback [9]. In this way,most exchange students in China are more likely to stay in China for further study or start their career than to return to their original place after finishing their established study career.

Compared to the results shown in the career planning of international students, this study linked the social adaptability of international students to their later career planning and found a connection between them.

The major limitation of this study can be summarized as this paper does not make a classification and comparison of international students according to academic types. More investigations are needed to show the relationship between the academic types of international students and their motivations.

The Subsequent research will focus on refining the classification and exploring its correlation.

\section{ACKNOWLEDGMENTS}

First and foremost, I would like to show my deepest gratitude to my supervisor,PhD Liam Francis Gearon, Associate Professor, Department of Education, University of Oxford, a respectable, responsible and resourceful scholar, who has provided me with valuable guidance of this thesis. Without his enlightening instruction, impressive kindness and patience, I could not have completed my thesis. His keen and vigorous academic observation enlightens me not only in this thesis but also in my future study. I shall extend my thanks to Chenkai Chi,Joint PhD student in Educational
Studies, for all her kindness and help. Last but not least, I' d like to thank all my family for their encouragement and support.

\section{REFERENCES}

[1] Liu ZM\&Z Yang 2018.The spatial spillover effect of foreign students from "The Belt and Road" countries on China's economic growth:1-9.

[2] John W Berry. Immigration, Acculturation, and Adaptation [J] . Applied Psychology, 1997 (1) : 5-34.

[3] Blake H ,Rosen D and R. Kelly Aune. An analysis of friendship networks, social connectedness , homesickness, and satisfaction levels of international students[J]. International journal of intercultural relations, 2011( 35) : 281-295.

[4] Spencer -Rodgers J \& M Timothy. The attitudes toward the culturally different: the role of intercultural communication barriers, affective responses, consensual stereotypes, and perceived threat [J]. International journal of intercultural relations, 2002(26) : 609-631.

[5] Oberg K. Cultural shock: Adjustment to new cultural environments[J]. Practical Anthropology, 1960, 7: 177-182.

[6] Gullahorn J. T., Gullahorn J. E. An Extension of the U-Curve Hypothesis[J]. Journal of Social Issues, 1963, 19(3): 33-47.

[7] CLINCIU AU REL ION. Adaptation and stress for the first year university students $[\mathrm{J}]$. Procedia Social and behavioral sciences, 2013(78) : 718722.

[8] Ma J.The cultural connotation and social extension of the difference between Chinese and western $\operatorname{diet}[\mathrm{J}] J$ Journal of Shenyang University of Technology (Social Science Edition)2011,4: 377-380 .

[9] John W Berry. Immigration, Acculturation, and Adaptation [J] . Applied Psychology, 1997 (1) : 5-34.

[10] The Ministry of Education. Statistics on overseas study in China in 2019. [EB/OL] .(2019- 0219) The Ministry of Education and four provinces and cities signed the Memorandum of International Cooperation on Promoting "the Belt and Road" Education Action. http://www.moe.gov.cn/ jyb_xwfb/gzdt_gzdt/moe_1485/201902/t20190219 370193.html 
[11] The Ministry of Education. Statistics on overseas study in China in 2018. [EB/OL] . ( 2019- 04 - 27) [2020 - 04-10] . http: / /www. moe. gov. cn / jyb _ xwfb / gzdt _ gzdt /s5987/201904/t20190412_ 377692. html.

[12] The Ministry of Education.From 2016 to 2019, $80 \%$ of overseas students returned home after completing their studies. 2020-12-22. http://www.moe.gov.cn/fbh/live/2020/52834/mtbd/ 202012/t20201222_506994.html

[13] The Ministry of Education.The number of Chinese-foreign cooperatively-run schools and programs has reached 2,332and1,230.2020-12-22. http://www.moe.gov.cn/fbh/live/2020/52834/mtbd/ 202012/t20201222_506955.html 